\title{
MORFEM BAHASA MELAYU RIAU DIALEK SIAK DI DESA REMPAK KECAMATAN SABAK AUH KABUPATEN SIAK PROVINSI RIAU
}

\author{
Mira Nazira \\ SMP Negeri 2 Siak, Indonesia \\ myera.nazira@yahoo.com
}

\begin{abstract}
This study of "Morpheme Malay Riau Dialect Of Siak In The Village OfUnisow Subdistrict Sabak Auh Siak, Riau Province". The problem in this research is how the morphemes are bound, which are in malay Riau Province? This study iams to collect, analyze, deserige and concluede morpheme bound contained in the Malay Riau dialect of Siak in the Village Of Unison Subdistrict Sabak Auh Siak Regency Of Riau Province. The main data souvees in dualitative research is the speech of informans who originated from the Malay Riau Dialect Of Siak In The Village Of Unision Subdististrict Sabak Auh Siak Regency Of Riau Province. The data obtained in this study is a morpheme gound to that contained in the utterance that is pronounced by the informant. The method that I use in the implementation of this research method descriptive. Data collection techniques this research uses observasion techniques, interviews, recordings, listen and record. From the results obtained it can be concluded that the morpheme malay Riau dialect of Siak in the village of unison Subdistrict Sabak Auh Siak regency of Riau Province consists of (1) Prefix (prefix), hit, search, split, divide, paint, crusty, hanging, gilard, forgetful, destroyer, for, will, (2) Infiks (insert), bars, cruising (3) suffixes (ending), love, reconcile, food, (4) confix (prefix and suffix), cleverness, planning, coming.
\end{abstract}

Keywords: morpheme bound, Melayu Lenguage, Siak

\begin{abstract}
ABSTRAK
Penelitian ini berjudul "Morfem Bahasa Melayu Riau dialek Siak di desa Rempak Kecamatan Sabak Auh Kabupaten Siak Provinsi Riau”. Masalah dalam penelitian ini adalah bagaimanakah morfem terikat yang terdapat dalam bahasa Melayu Riau Dialek Siak di Desa Rempak Kecamatan Sabak Auh Kabupaten Siak Provinsi Riau?Penelitian ini bertujuan untuk mengumpulkan, menganalisis, mendeskripsikan dan menyimpulkan morfem terikat yang terdapat dalam bahasa Melayu Riau dialek Siak di Desa Rempak Kecamatan Sabak Auh Kabupaten Siak Provinsi Riau. Sumber data utama dalam penelitian kualitatif adalah tuturan informan yang berasal dari bahasa Melayu Riau dialek Siak di Desa Rempak Kecamatan Sabak Auh Kabupaten Siak Provinsi Riau. Data yang diperoleh dalam penelitian ini adalah morfem terikat yang terdapat dalam tuturan yang diucapkan oleh informan. Metode yang penulis gunakan dalam pelaksanaan penelitian ini metode deskriptif.Teknik pengumpulan data penelitian ini menggunakan teknik observasi, wawancara, rekaman, simak dan catat. Dari hasil yang diperoleh maka dapatlah disimpulkan bahwa morfem terikat bahasa Melayu Riau dialek Siak di Desa Rempak Kecamatan Sabak Auh Kabupaten Siak Provinsi Riau terdiri atas (1) prefiks (awalan) $\{$ di- $\}$ [ditukuwe] 'dipukul', $\left\{\right.$ ma- $\left.^{\mathrm{w}}\right\}\left[\mathrm{manca}^{\mathrm{y}}\right]$ 'mencari', [mambagi] 'membagi', [mancat] 'mengecat', \{ba- $\}$ [bakoya?] 'berkerak', \{ta- $\}$ [tagantoๆ] 'tergantung', \{paN-\} [panjago] 'penjaga', \{pa- $\}$ [palUpo] 'pelupa', \{par-\} [pausa?] 'perusak', \{sa\} [saumu] 'seumur', \{ka-\} [kaכnda?] 'kehendak', (2) infiks (sisipan) \{-am-\} [kamunion] 'kemuning', \{-ar-\} [tarali] 'terali', \{-al-\} [jalojah] 'jelajah', (3) sufiks (akhiran) $\{-\mathrm{i}\}$ [sayangi] 'sayani', \{-kan\} [damaikan] 'damaikan', \{-an\} [makanan] 'makanan', (4) konfiks (awalan dan akhiran), \{ka-an\} [kapandai $\left.{ }^{y} a n\right] ~ ' k e p a n d a i a n ', ~\{p e r-a n\}$ [parancanaan] 'perencanaan', \{ber-an $\}$ [badatanan] 'berdatangan'.
\end{abstract}

Kata Kunci: morfem terikat, bahasa Melayu, Siak

Morfem Bahasa Melayu Riau Dialek Siak di Desa Rempak Kecamatan Sabak Auh Kabupaten Siak Provinsi Riau 


\section{PENDAHULUAN}

Linguistik adalah ilmu yang membahas tentang bahasa, ilmu yang mengkaji selukbeluk bahasa secara dalam.Chaer (2012:3) mengemukakan linguistik adalah "Ilmu tentang bahasa, atau ilmu yang menjadikan bahasa sebagai objek kajianya.'Ilmu linguistik sering juga disebut linguistik umum. Artinya, ilmu linguistik itu tidak hanya mengkaji sebuah bahasa saja, seperti bahasa Jawa, bahasa Arab, tetapi mengkaji seluk beluk bahasa pada umumnya, bahasa yang menjadi alat interaksi sosial milik manusia.

Salah satu cabang ilmu linguistik yang mempelajari perubahan kata disebut morfologi, dengan kata lain morfologi membahas perubahan makna kata dan bentuk kata. Menurut Ramlan (2001:21) "Morfologi adalah bagian dari ilmu bahasa yang membicarakan atau yang mempelajari selukbeluk bentuk kata serta pengaruh perubahanperubahan bentuk kata terhadap golongan dan arti kata, atau dengan kata lain dapat dikatakan morfologi mempelajari seluk-beluk bentuk kata serta fungsi perubahan-perubahan bentuk kata itu, baik fungsi gramatik maupun fungsi semantik." Sejalan dengan pernyataan tersebut, Chaer (2008:3) berpendapat "Morfologi merupakan terbentuknya kata dalam bentuk dan makna sesuai dengan keperluan dalam satu tindak pertuturan.'Kata merupakan satuan yang terbesar dalam morfologi, sedangkan morfem merupakan satuan yang terkecil.Kemudian, Mulyono (2013:1) menjelaskan "Morfologi adalah ilmu bahasa yang mempelajari seluk-beluk wujud morfem." Batasan lain, yang tertuang dalam Kamus Besar Bahasa Indonesia, berbunyi bahwa morfologi cabang Linguistik tentang morfem dan kombinasi-kombinasinya. Secara populer, morfologi dibatasi dengan cabang ilmu bahasa yang mempelajari seluk-beluk bentuk kata."Dari beberapa pendapat ahli, dapat disimpulkan bahwa morfologi merupakan ilmu yang mempelajari atau mengkaji terbentuk dan perubahannya kata dan seluk-beluk wujud morfem.

Penulis hanya meneliti bagian morfologi yaitu morfem, morfem merupakan satuan terkecil. Ramlan (1997:32) berpendapat
"Morfem ialah satuan gramatik yang paling kecil; satuan gramatik yang tidak mempunyai satuan lain sebagai unsurnya." Sejalan dengan pernyataan tersebut Chaer (2008:13) berpendapat "Morfem adalah satuan gramatikal terkecil yang memiliki makna." Kemudian, Charlina dan Sinaga (2006:6-7) menjelaskan "Morfem merupakan satuan bahasa yang paling kecil yang tidak dapat dibagi lagi atas unsur-unsur pembentuknya," makna yang dimaksudkan yang terkandung, dalam tiap morfem ialah baik makna leksikal maupun makna gramatikal.Misalnya sering dijumpai kata-kata; sakit penyakit, pesakitan.Tiap kata itu memberikan makna tertentu seperti yang dapat dilihat di dalam kamus.Makna yang dimaksud adalah makna leksikal. Namun, perlu diketahui bahwa kata sakit tidak sama artinya dengan penyakit dan tidak sama pula artinya dengan pesakitan. Penyakit adalah hasil hasil bentukan morfemmorfem pe-+sakit dan pesakitan adalah hasil bentukan morfem-morfem pe-+sakit+-an. Tambahan morfem pe- pada sakit mengubah makna sakit yang semula. Demikan juga tambahan morfem pe- dan -an pada morfem sakit itu menimbulkan makna lain. Baik pemaupun pe-t-an berfungsi gramtikal dan memberikan makna gramatikal dalam katakata bentukan itu, sebab pe- saja, -an saja, atau pe-t-an saja tidak mengandung makna apaapa.

Morfem yang penulis teliti ini morfem bahasa daerah.Bahasa daerah merupakan alat komunikasi sebagaian masyarakat, terutama masyarakat pedesaan.Bahasa daerah biasanya dipakai dirumah sebagai bahasa ibu dan digunakan dalam komunikasi antar keluarga.Bahasa daerah masih memegang peranan penting dalam kehidupan masyarakat pedesaan.Kridalaksana (2005:25) berpendapat, "Bahasa daerah adalah bahasa yang dipergunakan penduduk asli suatu daerah, biasanya dalam wilayah multingual, dipertentangkan dengan bahasa persatuan, dan bahasa nasional".Setiap suku bangsa memiliki suatu bahasa, sebagai alat untuk mengadakan komunikasi antara anggota masyarakatnya. Indonesia dikenal sebagai salah satu negara yang memiliki ratusan bahasa daerah. Selain 
itu, Indonesia juga terdiri atas berbagai pulau dan didiami oleh berbagai jenis suku bangsa, masing-masing daerah memiliki bahasa dan dialek-dialek yang khas. Salah satunya, adalah bahasa Melayu Riau Dialek Siak khususnya di Desa Rempak Kecamatan Sabak Auh Kabupaten Siak Provinsi Riau.

Kabupaten Siak adalah salah satu nama kabupaten yang ada di Provinsi Riau. Secara geografis kabupaten Siak terletak pada koordinat 10 16' 30-00 20'49 Lintang Utara dan 100 54' $30^{\prime} 102^{\circ} 10^{\prime}$ 59' Bujur Timur. Selain dikenal dengan sungai Siak yang membelah wilayah kabupaten Siak, daerah ini juga ini juga terdapat banyak tasik atau danau yang tersebar dibeberapa wilayah kecamatan. Sungai Siak terkenal sebagai sungai terdalam di tanah air. Kabupaten Siak Mempunyai 14 kecamatan salah satunya Kecamatan Sabak Auh, kecamatan ini terletak pada ujung kabupaten Siak. Kecamatan Sabak Auh mempunyai beberapa desa, diantaranya Desa Rempak. Desa Rempak dekat dengan perbatasan antara Siak dan Bengkalis, (sumber: kantor Camat Sabak Auh).

Bahasa Melayu Riau Dialek Siak di

Desa Rempak Kecamatan Sabak Auh Kabupaten Siak Provinsi Riau merupakan bahasa perhubungan masyarakat Siak.Masyarakat Desa Rempak menggunakan bahasa Melayu dalam kehidupan seharihari.Ruang lingkup pemakaiannya meliputi lingkungan yang cukup luas, termasuk semua tempat dan situasi, mulai dari pendatang, agama, adat-istiadat, sampai dengan lingkungan pekerjaan.

Peneliti merasa tertarik untuk melakukan penelitian yang berjudul "Morfem Bahasa Melayu Riau Dialek Siak di Desa Rempak Kecamatan Sabak Auh Kabupaten Siak Provinsi Riau."Menurut penulis bahwa bahasa melayu Riau dialek Siak di Desa Rempak Kecamatan Sabak Auh Kabupaten Siak provinsi Riau memiliki morfem terikat.Penomena morfem terikat bahasa Melayu Riau Dialek Siak yaitu: [ba+obui] 'di+rebus', [ba+langgo] 'ter+tabrak', [ba+humban] 'di+buang.' Alasan peneliti memilih penelitian tentang Morfem karena penelitian sebelumnya telah dilakukan di daerah yang sama meneliti tentang Fonologi dan Afiksasi. Oleh karena itu peneliti lebih tertarik pada morfem, dan juga lebih memahami tentang Morfem.

Tujuan penulis meneliti di Desa Rempak yang pertama karena peneliti merupakan penduduk asli Desa Rempak Kecamatan Sabak auh kabupaten Siak Provinsi Riau, penulis lahir dan dibesarkan di daerah tersebut.Kedua untuk memperkenalkan kepada pembaca bahwa di daerah Siak tidak hanya memiliki fonologi dan afiksasi tetapi juga memiliki morfem terikat.Oleh karena itu, peneliti tertarik untuk mengambil bahasa Melayu Riau Dialek Siak di Desa Rempak Kecamatan Sabak Auh Kabupaten Siak Provinsi Riau sebagai objek kajian penelitian. Kemudian penelitian ini bersifat untuk mendokumentasikan Morfem Bahasa Melayu Riau Dialek Siak di Desa Rempak Kecamatan Sabak Auh Kabupaten Siak Provinsi Riau, supaya di kedapan hari apabila terjadi perubahan bahasa maka masih ada data-data yang tersimpan tentang Morfem Bahasa Melayu Riau Dialek Siak di Desa Rempak Kecamatan Sabak Auh Kabupaten Siak Provinsi Riau.

Penelitian yang peneliti lakukan ini merupakan penelitian lanjutan, dan pada wilayah yang berbeda.Penelitian tentang morfem sudah pernah diteliti sebelumnya. Oleh Putri Wulandari dalam jurnal, mahasiswa Fakultas Keguruan dan Ilmu Pendidikan Universitas Medan tahun 2012 dengan judul "Afiksasi Bahasa Jawa dan Bahasa Sunda Dalam Bahasa Indonesia." Masalah dari penelitian ini yaitu bagaimanakah bentuk afiksasi bahasa Jawa dan bahasa Sunda? Penelitian ini menggunakan teori Ramlan (1997).Teknik yang digunakan adalah teknik observasi, wawancara, rekaman dan teknik catat.Hasil penelitian Putri Wulandari menggambarkan banyak sekali bentuk-bentuk afiksasi dalam bahasa Jawa dan bahasa Sunda.Afiksasi ini terdiri dari prefiks, sufiks, infiks. Penelitian Putri Wulandari dan penulis mempunyai persamaan dan perbedaan diantaranya yaitu persamaannya sama sama mengakaji morfologi perbedaanya daerah yang diteliti berbeda dengan daerah penulis.

Penelitian selanjutnya oleh Mardarisna, mahasiswa Fakultas Keguruan dan Ilmu 
Pendidikan Universitas Islam Riau tahun 2012 dengan judul "Morfem Bahasa Melayu Riau dialek Tembilahan Desa Kota Baru Kecamatan Keritang Kabupaten Indragiri Hilir." Masalah dari peneliti sebelumnya yaitu, (a) morfem terikat apa saja yang terdapat dalam bahasa Melayu Riau dialek Tembilahan Desa Kota Baru Kecamatan Keritang Kabupaten Indragiri Hilir? (b) apa makna morfem terikat bahasa Melayu Riau dialek Tembilahan Desa kota Baru Kecamatan Kerintang Kabupaten Indragiri Hilir? Teori yang digunakan adalah teori Alwi, dkk.(2003). Teknik yang digunakan adalah teknik observasi, wawancara, rekaman dan teknik catat.Hasil penelitiannya menggambarkan di dalam bahasa Melayu Riau dialek Tembilahan Desa Kota Baru Kecamatan Kerintang Kabupaten Indragiri Hilir memiliki morfem terikat dan makna morfem terikat bahasa Melayu Riau Dialek Tembilahan, semua morfem terikatnya memiliki makna.Penelitian Mardarisna dengan penelitian yang penulis lakukan memiliki perbedaan dan persamaan.Perbedaannya dari segi tempat penelitian, objek dan penelitian.Penulis meneliti didaerah Siak dan objek penelitian bahasa Melayu dialek Siak, sedangkan objek penelitian Mardarisna bahasa Melayu Riau dialek Tembilahan.Persamaan penelitian ini sama-sama mengkaji tentang morfem.

Penelitian relevan selanjutnya diambil dari jurnal oleh Zulfika Harlina Fakultas Keguruan dan Ilmu Pendidikan Universitas Maritim Raja Ali Haji Tanjung Pinang pada tahun 2013 dengan judul “ Analisis Morfem Bebas dan Morfem Terikat Sub Dialek Melayu Pancur Kabupaten Lingga" , masalah pada penelitian ini (a) apa sajakah morfem bebas sub dialek Melayu Pancur Kabupaten Lingga (b) apa sajakah morfem terikat sub dialek Melayu Pancur Kabupaten Lingga

Teori yang digunakan teori Chaer
(2006).Teknik pengumpulan data
menggunakan teknik observasi dan interview bebas.Hasil penelitian ini adalah morfem kata dasar dan morfem terikat yaitu prefiks dan infiks. Adapun prefiks tersebut yaitu /bə-/, /to/, /mə-/, /sə-/, infiks yaitu /-əm-/ dan /-əl/, dan empat jenis kata yang terdapat dalam morfem bebas dan morfem terikat yaitu kata sifat, kata kerja, kata keterangan, dan kata benda. Penelitian Zulfika Harlina dengan penenlitian yang penulis lakukan memiliki perbedaan dan persamaan.Perbedaanya dari segi tempat penelitian, penulis melalukan penenlitian di Rempak sedangkan penelitian sebelumnya di Tanjung Pinang.Persamaan dari penelitian ini sama-sama mengkaji tentang morfem terikat. Penelitian relevan selanjutnya dilakukan oleh Nina, Universitas Islam Riau pada tahun 2014 yang berjudul "Morfem Bahasa Melayu Riau Dialek Tarempa Kecamatan Siantan Kabupaten Kepuluan Anambas." Masalah dari penelitian Nina yaitu, (a) Morfem terikat apa sajakah yang terdapat di dalam bahasa Melayu Riau dialek Tarempa Kecamatan Siantan Kabupaten Kepulauan Anambas?, (b) Bagaimanakah alomorf morfem terikat bahasa Melayu Riau dialek Tarempa Kecamatan Siantan Kabupaten Kepulauan Anambas?, (c) Apa makna morfem terikat bahasa Melayu Riau dialek Tarempa Kecamatam Siantan Kabupaten Kepulaua Anambas?. Teori yang digunakan adalah teori Ramlan (2001) dan Chaer (2008).Teknik yang digunakan adalah teknik observasi, wawancara, rekaman dan teknik catat. Hasil penelitian Nina menggambarkan bahwa bahasa Melayu Riau dialek Tarempa Kecamatam Siantan Kabupaten Kepulauan Anambas memiliki morfem terikat, alomorf morfem terikat dan makna morfem terikat. Penelitian yang Nina dengan penelitian penulis lakukan memiliki perbedaan dan persamaan.Perbedaanya dari segi tempat penelitian, objek dan penelitian.Penulis meneliti daerah Kabupaten Siak Kecematan Sabak Auh Desa Rempak dan objek penelitian bahasa Melayu Siak, sedangkan penelitian Nina objek penelitian bahasa Melayu Riau dialek Terempa, dan penelitian Nina mengkajii alomorf sedangkan penelitian penulis tidak.Persamaannya samasama megkaji tentang morfem terikat dan makna morfem terikat.

Penelitian selanjutnya dilakukan oleh Nurhaida mahasiswa FKIP Universitas Islam Riau pada tahun 2016 dengan judul "Morfem Terikat Bahasa Melayu Riau dialek Kampar Desa Pantai Cermin Kampung Kota Batak Kabupaten Kampar." Masalah pada peneliti sebelumnya yaitu, (a) morfem terikat apa 
sajakah yang terdapat di dalam bahasa Melayu Riau dialek Kampar Desa Pantai Cermin Kampung Kota Batak Kabupaten Kampar? Teori yang digunakan adalah teori linguistik struktural dan berbagai ahli sebagai acuan dalam penelitian.Teknik yang digunakan adalah teknik observasi (pengamatan), wawancara, teknik rekaman, dan teknik catatan. Hasil penelitiannya menggambarkan di dalam bahasa Melayu Riau dialek Kampar Desa Pantai Cermin Kampung Kota Batak Kabupaten Kampar memiliki morfem terikat. Penelitian Nurhaida dengan penelitian yang penulis lakukan memiliki perbedaan dan persamaan.Perbedaan penelitian ini dari segi tempat penelitian, objek dan penelitian.Penulis melakukan penelitian di Desa Rempak dan objek penelitian ini bahasa Melayu dialek Siak, sedangkan objek penelitian sebelumnya bahasa Melayu Riau dialek Kampar.Persamaan penelitian ini sama-sama mengkaji tentang morfem terikat.

Penelitian ini diharapkan dapat memberikan manfaat, baik manfaat teoretis dan manfaat praktis. Manfaat teoretis penelitian ini dapat memperkaya disiplin ilmu yang berkaitan dengan linguistik dan kebahasaan khususnya bidang morfologi. Manfaat praktis penelitian yaitu penelitian ini diharapkan bermanfaat bagi peneliti dan pembaca: (1) Untuk peneliti, menambahkan pengetahuan wawasan dengan dilakukan penelitian ini selain itu aplikasi penerapan morfologi, (2) Untuk pembaca, diharapkan dapat dijadikan rujukan dalam melakukan penelitian dalam bidang sejenis.

\section{METODOLOGI PENELITIAN}

Metode penelitian yang digunakan adalah metode deskriptif. Sugiyono (2008:85) mengemukakan "Metode deskriptif adalah jenis metode yang mendeskripsikan dan menggambarkan terhadap objek yang diteliti melalui data sampel atau populasi sebagaimana adanya, tanpa melakukan analisis dan membuat kesimpulan yang berlaku untuk umum". Selain itu, Sujarweni (2014:11) juga berpendapat "Penelitian deskriptif adalah penelitian yang dilakukan untuk mengetahui nilai masing-masing variabel, baik satu variabel atau lebih sifatnya independen tanpa membuat hubungan maupun perbandingan dengan variabel lain." Pendekatan dalam penelitian ini adalah pendekatan kualitatif, seperti diungkapkan oleh Moleong (2014:6) "Penelitian kualitatif adalah penelitian yang bermaksud untuk memahami fenomena tentang apa yang dialami oleh subjek penelitian misalnya perilaku, persepsi, motivasi, tindakan, secara holistik, dan dengan cara deskripsi dalam bentuk kata-kata dan bahasa, pada suatu konteks khusus yang alamiah dan dengan memanfaatkan berbagai metode alamiah." Hal ini disebabkan oleh pengolahan data penelitian ini tanpa menggunakan unsur-unsur perhitungan (statistik). Penelitian ini termasuk ke dalam jenis penelitian lapangan. Menurut Moleong (2014:26) "Penelitian lapangan dapat juga dianggap sebagai pendekatan luas dalam penelitian kualitatif atau sebagai metode untuk mengumpulkan data kualitatif." Ide pentingnya adalah bahwa peneliti berangkat ke 'lapangan' untuk mengadakan pengamatan tentang sesuatu fenomena dalam suatu keadaan alamiah.

\section{HASIL DAN PEMBAHASAN}

Prefiks \{di-\} Bahasa Melayu Riau Dialek Siak

$$
\begin{aligned}
& {\left[\text { ditukuwe }^{\mathrm{w}}\right]} \\
& d i-+ \text { tuku }^{w} e \rightarrow \text { dituku }^{w} e
\end{aligned}
$$

Berdasarkan data 1 terdapat data morfem [ditukuwe], kata [ditukuwe] teridiri dari dua morfem yaitu morfem bebasnya adalah $\left\{t u k u^{w} e\right\}$ morfem terikatnya $\{d i-\}$. Proses terbentuknya kata $\left\{\right.$ ditukuwe $^{w}$ \} adanya proses penambahan prefiks \{di-\} pada kata [tuku $\left.{ }^{w} e\right]$, proses dari membentuk kata [ditukuwe] terdapat afiks $\{d i\}+\left\{t u k u^{w} e\right\},\{d i-\}$ termasuk dalam kategori prefiks sedangkan [tukuwe] termasuk dalam kategori kata dasar. Tujuan dari proses penggabungan antara dua morfem $\{d i-\}$ dan $\left\{t u k u^{w} e\right\}$ yaitu agar prefiks $\{d i-\}$ mempunyai arti dan makna karena prefiks $\{d i-$ \} tidak dapat memiliki arti. Sesuai penjabaran data 1 dapat disimpulkan bahwa prefiks \{di-\} akan memiliki arti apabila dilakukan proses penggabungan dengan morfem bebas seperti [ditukuwe] artinya 'dipukul'. Dengan demikian dapat dinyatakan bahwa di dalam bahasa Melayu Riau dialek Siak di Desa Rempak 
Kecamatan Sabak Auh Kabupaten Siak Provinsi Riau memiliki morfem terikat dan prefiks $\{d i-\}$.

\section{Prefiks \{ma-\} Bahasa Melayu Riau Dialek Siak}

[manca $\left.{ }^{\mathrm{y}}\right]$

$$
\text { man- }+ \text { ca }^{y} \rightarrow \text { manca }^{y}
$$

Di dalam data 59 menunjukkan data morfem $\left[\right.$ manca $\left.^{y}\right]$, kata $\left[\mathrm{manca}^{y}\right]$ terdiri dari dua morfem yaitu morfem terikat dan morfem bebas. Morfem bebasnya adalah $\left\{\mathrm{ca}^{y}\right\}$ morfem terikatnya $\{m a-N\}$. Proses terbentuknya kata $\left[\right.$ manca $\left.^{y}\right]$ adanya proses penambahan prefiks $\{m a-N\}$ pada kata $\left[\mathrm{Ca}^{y}\right]$, proses dari membentuk kata [manca $\left.{ }^{y}\right]$ terdapat afiks $\{m a-$ $N\}+\left\{\mathrm{ca}^{y}\right\},\{m a-N\}$ termasuk dalam kategori prefiks sedangkan $\left[\mathrm{maca}^{y}\right]$ termasuk dalam kategori kata dasar. Fungsi prefiks dalam kata [manca $\left.{ }^{y}\right]$ adalah untuk membentuk kata berimbuhan. Tujuan dari proses penggabungan antara dua morfem $\{m a-N\}$ dan $\left\{\mathrm{ca}^{y}\right\}$ supaya prefiks $\{m a-N\}$ mempunyai arti dan makna karena prefiks $\{m a-N\}$ tidak dapat memiliki arti. Sesuai penjabaran data 59 dapat disimpulkan bahwa prefiks $\{m a-N\}$ akan memiliki arti apabila dilakukan proses penggabungan dengan morfem bebas seperti [manca $\left.{ }^{y}\right]$ artinya 'mencari'. Dengan demikian dapat dinyatakan bahwa di dalam bahasa Melayu Riau dialek Siak di Desa Rempak Kecamatan Sabak Auh Kabupaten Siak Provinsi Riau memiliki morfem terikat dan prefiks $\{m a-N\}$.

\section{Prefiks \{Ba-\} Bahasa Melayu Riau Dialek Siak}

$$
\begin{aligned}
& \text { [bakつya?] } \\
& b a-+k \supset \gamma a ? \rightarrow b a k \supset \gamma a ?
\end{aligned}
$$

Berdasarkan data 21 terdapat data morfem

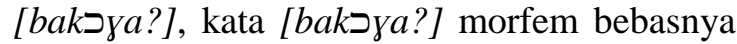

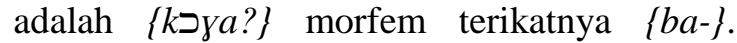
Proses terbentuknya kata \{bakつya?\} adanya proses penambahan prefiks $\{b a-\}$ pada kata

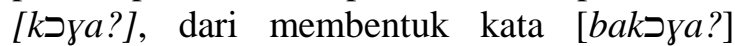
terdapat afiks $\{b a-\}+\left\{k \supset_{\gamma} a ?\right\},\{b a-\}$ termasuk dalam kategori prefiks sedangkan [kつya?] termasuk dalam kategori kata dasar. Fungsi prefiks dalam kata [bakつya?] adalah untuk membentuk kata berimbuhan. Tujuan dari proses penggabungan antara dua morfem $\{b a-\}$ dan $\{k \supset y a ?\}$ yaitu agar prefiks $\{b a-\}$ mempunyai arti dan makna karena prefiks $\{b a-$ \} tidak dapat memiliki arti. Sesuai penjabaran data 21 dapat disimpulkan bahwa prefiks $\{b a-\}$ akan memiliki arti apabila dilakukan proses penggabungan dengan morfem bebas seperti [bakつya?] artinya 'berkerak'. Dengan demikian dapat dinyatakan bahwa di dalam bahasa Melayu Riau dialek Siak di Desa Rempak Kecamatan Sabak Auh Kabupaten Siak Provinsi Riau memiliki morfem terikat dan prefiks $\{b a-\}$.

Prefiks $\{\mathrm{Ta}-\}$ Bahasa Melayu Riau Dialek Siak

27. [taso]

$$
\text { ta- }+ \text { aso } \rightarrow \text { taso }
$$

Diketahui data 27 terdapat data morfem [taso], kata [taso] terdiri dari dua morfem, morfem bebasnya adalah $\{$ aso $\}$ morfem terikatnya $\{t a-$ \}. Proses terbentuknya kata \{taso\} adanya proses penambahan prefiks \{ta-\} pada kata [aso]. Dari penggabungan kedua morfem mendapatkan hasil kata \{taso\}, dimana penggabungan hasil dari membentuk kata [taso] terdapat afiks $\{t a-\}+\{a s o\}$, akan terjadi penghilangan fonem $/ \mathrm{o} /,\{t a-\}$ termasuk dalam kategori prefiks sedangkan [aso] termasuk dalam kategori kata dasar. Fungsi prefiks dalam kata [taso] adalah untuk membentuk kata berimbuhan. Tujuan dari proses penggabungan antara dua morfem \{ta-\} dan \{aso $\}$ yaitu agar prefiks $\{t a-\}$ mempunyai arti dan makna karena prefiks $\{t a-\}$ tidak dapat memiliki arti. Sesuai penjabaran data 27 dapat disimpulkan bahwa prefiks $\{t a-\}$ akan memiliki arti apabila dilakukan proses penggabungan dengan morfem bebas seperti [taso] artinya 'terasa'. Dengan demikian dapat dinyatakan bahwa di dalam bahasa Melayu Riau dialek Siak di Desa Rempak Kecamatan Sabak Auh Kabupaten Siak Provinsi Riau memiliki morfem terikat dan prefiks $\{t a-\}$.

Prefiks \{pa-\} Bahasa Melayu Riau Dialek Siak

$$
\begin{aligned}
& \text { 34. [palUpo] } \\
& \qquad p a-+10 p o \rightarrow \text { palUpo }
\end{aligned}
$$

Diketahui data 34 terdapat data kata [palUpo], kata [palUpo] morfem bebasnya adalah $\{l U p o\}$ morfem terikatnya $\{p a-\}$. Proses terbentuknya kata \{ palUpo\} adanya proses penambahan prefiks $\left\{\mathrm{pa}^{-}\right\}$pada kata [lUpo], 
dari membentuk kata [palOpo] terdapat afiks $\{p a-\}+\{l U p o\},\{p a-\}$ termasuk dalam kategori prefiks sedangkan [lUpo] termasuk dalam kategori morfem bebas atau kata dasar. Fungsi prefiks dalam kata [palUpo] adalah untuk membentuk kata berimbuhan. Tujuan dari proses penggabungan antara dua morfem $\{p a-\}$ dan $\{l \cup p o\}$ yaitu agar prefiks $\{p a-\}$ mempunyai arti dan makna karena prefiks $\{p a-$ \} tidak dapat memiliki arti. Sesuai penjabaran data 34 dapat disimpulkan bahwa prefiks $\{\mathrm{pa}$ - $\}$ akan memiliki arti apabila dilakukan proses penggabungan dengan morfem bebas seperti [palUpo] artinya 'pelupa'. Dengan demikian dapat dinyatakan bahwa di dalam bahasa Melayu Riau dialek Siak di Desa Rempak Kecamatan Sabak Auh Kabupaten Siak Provinsi Riau memiliki morfem terikat dan prefiks $\{p a-\}$.

\section{Prefiks \{paN-\} Bahasa Melayu Riau Dialek Siak}

$$
\begin{aligned}
& \text { [pandape?] } \\
& \text { pan- + dap } \varepsilon ? \rightarrow \text { pandap } \varepsilon ?
\end{aligned}
$$

Berdasarkan data 40 terdapat data morfem [pandape?], kata [pandape?] morfem bebasnya adalah \{dape?\} morfem terikatnya \{paN-\}. Proses terbentuknya kata \{ pandape?\} adanya proses penambahan prefiks $\left\{\mathrm{paN}_{-}\right\}$pada kata [dape?], dari membentuk kata [pandape?] terdapat afiks $\{p a N-\}+\{$ dape?\}, \{paN-\} termasuk dalam kategori prefiks sedangkan [dape?] termasuk dalam kategori kata dasar. Fungsi prefiks dalam kata [pandape?] adalah untuk membentuk kata berimbuhan. Tujuan dari proses penggabungan antara dua morfem $\{p a N-\}$ dan \{pandape?\} yaitu agar prefiks $\{p a N-\}$ mempunyai arti dan makna karena prefiks $\{p a N-\}$ tidak dapat memiliki arti. Sesuai penjabaran data 40 dapat disimpulkan bahwa prefiks $\{p a N-\}$ akan memiliki arti apabila dilakukan proses penggabungan dengan morfem bebas seperti [pandape?] artinya 'pendapat'. Dengan demikian dapat dinyatakan bahwa di dalam bahasa Melayu Riau dialek Siak di Desa Rempak Kecamatan Sabak Auh Kabupaten Siak Provinsi Riau memiliki morfem terikat dan prefiks $\{p a N-\}$.

\section{Prefiks \{Sa-\} Bahasa Melayu Riau Dialek Siak}

$$
\begin{aligned}
& \text { [saumu] } \\
& \text { sa- + umu } \rightarrow \text { saumu }
\end{aligned}
$$

Berdasarkan data 49 terdiri dari kata [saumu], kata [saumu] terdiri dari dua morfem yaitu morfem $\{s a-\}$ dan morfem $\{u m u\}$ morfem bebasnya adalah $\{u m u\}$ morfem terikatnya $\{s a-$ \}. Proses terbentuknya kata\{saumu\} adanya proses penambahan prefiks $\{s a-\}$ pada kata [umu], dari membentuk kata [saumu] terdapat afiks $\{s a-\}+\{u m u\},\{s a-\}$ termasuk dalam kategori prefiks sedangkan [umu] termasuk dalam kategori kata dasar. Fungsi prefiks dalam kata [saumu] adalah untuk membentuk kata berimbuhan. Tujuan dari proses penggabungan antara dua morfem $\{s a-\}$ dan $\{u m u\}$ yaitu agar prefiks $\{s a-\}$ mempunyai arti dan makna karena prefiks $\{s a-\}$ tidak dapat memiliki arti. Sesuai penjabaran data 49 dapat disimpulkan bahwa prefiks $\{s a-\}$ akan memiliki arti apabila dilakukan proses penggabungan dengan morfem bebas seperti [saumu] artinya 'seumur'. Dengan demikian dapat dinyatakan bahwa di dalam bahasa Melayu Riau dialek Siak di Desa Rempak Kecamatan Sabak Auh Kabupaten Siak Provinsi Riau memiliki morfem terikat dan prefiks $\{s a-\}$.

\section{Infiks \{-am-\} Bahasa Melayu Riau Dialek Siak}

$$
\begin{aligned}
& \text { [kamuniכๆ] }
\end{aligned}
$$

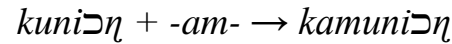

Diketahui data 55 memiliki data kata [kamuni $\eta$ ], kata [kamuni $\eta]$ morfem bebasnya adalah $\{k u n i \supset \eta\}$ morfem terikatnya $\{$-am-\}. Proses terbentuknya kata \{kamuniכ $\eta\}$ adanya proses penambahan infiks $\{$-am- $\}$ pada

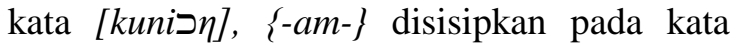
$\{k u n i \supset \eta\}$, dari membentuk kata [kamuni $\eta]$ terdapat afiks $\{-a m-\}+\{k u n i \supset \eta\},\{-a m-\}$ termasuk dalam kategori infiks sedangkan

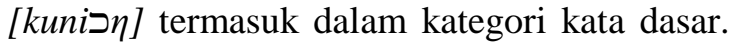
Fungsi infiks dalam kata [kamuni $\eta$ ] adalah untuk membentuk kata berimbuhan.Tujuan dari proses penggabungan antara dua morfem $\{-a m-\}$ dan $\{k u n i \supset \eta\}$ yaitu agar infiks $\{-a m-\}$ mempunyai arti dan makna karena prefiks $\{$ $a m-f$ tidak dapat memiliki arti.Sesuai penjabaran data 55 dapat disimpulkan bahwa infiks \{-am-\} akan memiliki arti apabila dilakukan proses penggabungan dengan 


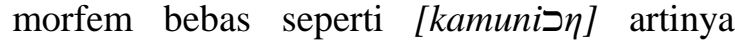

'kemuning'. Dengan demikian dapat dinyatakan bahwa di dalam bahasa Melayu Riau dialek Siak di Desa Rempak Kecamatan Sabak Auh Kabupaten Siak Provinsi Riau memiliki morfem terikat dan infiks \{am- $\}$.

\section{Infiks \{-ar-\} Bahasa Melayu Riau Dialek Siak}

[tarali]

$$
\text { tali }+ \text {-ar- } \rightarrow \text { tarali }
$$

Berdasarkan data 57 terdapat data kata [tarali], kata [tarali] morfem bebasnya adalah \{tali\} morfem terikatnya $\{$-ar-\}. Proses terbentuknya kata \{tarali\} adanya proses penambahan infiks $\{$-ar- $\}$ pada kata [tali], \{ar-\} disisipkan pada kata \{tali\}, dari membentuk kata [tarali] terdapat afiks $\{-$ ar- $\}+$ $\{$ tali $\},\{$-ar- $\}$ termasuk dalam kategori infiks sedangkan [tali] termasuk dalam kategori kata dasar. Fungsi infiks dalam kata [tarali] adalah untuk membentuk kata berimbuhan. Tujuan dari proses penggabungan antara dua morfem $\{$-ar-\} dan \{tali\} yaitu agar infiks $\{$-ar- $\}$ mempunyai arti dan makna karena infiks $\{$-ar\} tidak dapat memiliki arti. Sesuai penjabaran data dapat disimpulkan bahwa infiks \{-ar-\} akan memiliki arti apabila dilakukan proses penggabungan dengan morfem bebas seperti [tarali] artinya 'terali'. Dengan demikian dapat dinyatakan bahwa di dalam bahasa Melayu Riau dialek Siak di Desa Rempak Kecamatan Sabak Auh Kabupaten Siak Provinsi Riau memiliki morfem terikat dan infiks $\{$-ar- $\}$.

\section{Sufiks $\{-i\}$ Bahasa Melayu Dialek Siak [jatuoi] jatuo $+-i \rightarrow$ jatuo $i$}

Berdasarkan data 68 terdapat data kata[jatuoi], kata [jatuoi] morfem bebasnya adalah $\{$ jatuo\} morfem terikatnya $\{-i\}$. Proses terbentuknya kata \{jatuoi\} adanya proses penambahan sufiks $\{-i\}$ pada kata [jatuo], penambahan afiks $\{-\mathrm{i}\}$ yang diletakkan pada akhir kata \{jatuo\} seperti [jatuhi], dari membentuk kata [jatuoi] terdapat afiks \{jatuo\} $+\{-i\},\{-i\}$ termasuk dalam kategori sufiks atau morfem terikat sedangkan [jatuo] termasuk dalam kategori kata dasar atau morfem bebas. Fungsi sufiks dalam kata [jatuoi] adalah untuk membentuk kata berimbuhan. Tujuan dari proses penggabungan antara dua morfem $\{-i\}$ dan $\{j a t u o\}$ yaitu agar sufiks $\{-i\}$ mempunyai arti dan makna karena sufiks $\{-i\}$ tidak dapat memiliki arti. Sesuai penjabaran data 68 dapat disimpulkan bahwa sufiks $\{-i\}$ akan memiliki arti apabila dilakukan proses penggabungan dengan morfem bebas seperti [jatuoi] artinya 'jatuhi'. Dengan demikian dapat dinyatakan bahwa di dalam bahasa Melayu Riau dialek Siak di Desa Rempak Kecamatan Sabak Auh Kabupaten Siak Provinsi Riau memiliki morfem terikat dan sufiks $\{-i\}$.

\section{Sufiks \{-kan\} Bahasa Melayu Dialek Siak [damaikan] damai $+-k a n \rightarrow$ damaikan}

Berdasarkan data kata [damaikan] pada data morfem bebasnya adalah \{damai\} morfem terikatnya $\{-k a n\}$. Proses terbentuknya kata \{damaikan\} adanya proses penambahan sufiks \{-kan\} pada kata [damai], penambahan afiks \{-kan\} yang diletakkan pada akhir kata \{damai\} seperti [damaikan], dari membentuk kata [damaikan] terdapat afiks \{damai $\}+\{$ kan\}, \{-kan\} termasuk dalam kategori sufiks atau morfem terikat sedangkan [damai] termasuk dalam kategori kata dasar atau morfem bebas. Fungsi sufiks dalam kata [damaikan] adalah untuk membentuk kata berimbuhan. Tujuan dari proses penggabungan antara dua morfem \{-kan\} dan \{damai\} yaitu agar sufiks $\{-k a n\}$ mempunyai arti dan makna karena sufiks $\{-k a n\}$ tidak dapat memiliki arti. Sesuai penjabaran data 70 dapat disimpulkan bahwa sufiks $\{-k a n\}$ akan memiliki arti apabila dilakukan proses penggabungan dengan morfem bebas seperti [damaikan] artinya 'damaikan'. Dengan demikian dapat dinyatakan bahwa di dalam bahasa Melayu Riau dialek Siak di Desa Rempak Kecamatan Sabak Auh Kabupaten Siak Provinsi Riau memiliki morfem terikat dan sufiks $\{-k a n\}$.

Konfiks \{ka-an\} Bahasa Melayu Riau Dialek Siak

78. [kapandai ${ }^{\mathrm{y} a n]}$

$$
k a-+ \text { pandai }+-a n \rightarrow \text { kapandai }{ }^{y} a n
$$

Berdasarkan data 78 terdapat data kata [kapandai $\left.{ }^{\mathrm{y}} a n\right]$, kata [kapandaìan] morfem bebasnya adalah \{pandai\} morfem terikatnya \{ka-an\}. Proses terbentuknya kata 
\{kapandai ${ }^{\mathrm{y}}$ an\} adanya proses penambahan konfiks \{ka-an\} pada kata [pandai] penambahan pada awal dan akhir kata seperti \{kapandai ${ }^{\mathrm{y}}$ an\}, dari membentuk kata [kapandaian] terdapat afiks $\{k a-a n\}+$ \{pandai\}, \{ka-an\} termasuk dalam kategori konfiks sedangkan [pandai] termasuk dalam kategori kata dasar. Fungsi konfiks dalam kata [kapandaiyan] adalah untuk membentuk kata berimbuhan. Tujuan dari proses penggabungan antara dua morfem \{ka-an\} pada kata dasar \{pandai\} yaitu agar konfiks \{ka-an\} mempunyai arti dan makna karena konfiks \{ka-an\} tidak dapat memiliki arti. Sesuai penjabaran data 78 dapat disimpulkan bahwa konfiks \{ka-an\} akan memiliki arti apabila dilakukan proses penggabungan dengan morfem bebas seperti [kapandai ${ }^{\mathrm{y} a n]}$ artinya 'kepandaian'. Dengan demikian dapat dinyatakan bahwa di dalam bahasa Melayu Riau dialek Siak di Desa Rempak Kecamatan Sabak Auh Kabupaten Siak Provinsi Riau memiliki morfem terikat dan konfiks \{ka-an\}.

\section{Konfiks \{per-an\} Bahasa Melayu Dialek Siak}

[parancanaan]

pa- + rancana + -an $\rightarrow$ parancanaan

Berdasarkan data terdapat data kata [parancnaan], kata [parancnaan] morfem bebasnya adalah \{rancna\} morfem terikatnya \{par-an\}. Proses terbentuknya kata \{ parancnaan $\}$ adanya proses penambahan konfiks \{par-an\} pada kata [rancna] penambahan pada awal dan akhir kata seperti \{parancnaan\}, dari membentuk kata [parOncnaan] terdapat afiks \{par-an\} + $\{$ rancna\}, \{par-an\} termasuk dalam kategori konfiks sedangkan [rancna] termasuk dalam kategori kata dasar. Fungsi konfiks dalam kata [parancnaan] adalah untuk membentuk kata berimbuhan. Tujuan dari proses penggabungan antara dua morfem \{par-an\} pada kata dasar \{rancnaan\} yaitu agar konfiks \{par-an\} mempunyai arti dan makna karena konfiks \{par-an\} tidak dapat memiliki arti. Sesuai penjabaran data dapat disimpulkan bahwa konfiks \{par-an\} akan memiliki arti apabila dilakukan proses penggabungan dengan morfem bebas seperti [parancnaan] artinya 'perencanaan'. Dengan demikian dapat dinyatakan bahwa di dalam bahasa Melayu Riau dialek Siak di Desa Rempak Kecamatan Sabak Auh Kabupaten Siak Provinsi Riau memiliki morfem terikat dan konfiks \{par-an\}.

\section{Konfiks \{ber-an\} Bahasa Melayu Riau Dialek Siak}

$$
\begin{aligned}
& \text { [badatanan }] \\
& \text { ba- }+ \text { datan }+ \text {-an } \rightarrow \text { badatanan }
\end{aligned}
$$

Berdasarkan data 89 menunjukkan data kata [badatayan], kata [badatayan] morfem bebasnya adalah $\{$ datay $\}$ morfem terikatnya \{bar-an\}. Proses pembentukan kata \{ badatayan $\}$ adanya proses penambahan konfiks \{bar-an\} pada kata [datay] penambahan pada awal dan akhir kata seperti \{badatayan\}, dari pembentukan kata [badatayan] terdapat afiks $\{$ bar-an $\}+\{$ datay $\}$, \{bar-an\} termasuk dalam kategori konfiks sedangkan [datay] termasuk dalam kategori kata dasar atau morfem bebas. Fungsi konfiks dalam kata [badatayan] adalah untuk membentuk kata berimbuhan. Tujuan dari proses penggabungan antara dua mofem bebas dan morfem terikat morfem \{bar-an\} pada kata dasar \{datay\} yaitu agar konfiks \{bar-an\} mempunyai arti dan makna karena konfiks \{bar-an\} tidak dapat memiliki arti. Sesuai penjabaran data 89 dapat disimpulkan bahwa konfiks \{bar-an\} akan memiliki arti apabila dilakukan proses penggabungan dengan morfem bebas seperti [badatayan] artinya 'berdatangan'. Dengan demikian dapat dinyatakan bahwa di dalam bahasa Melayu Riau dialek Siak di Desa Rempak Kecamatan Sabak Auh Kabupaten Siak Provinsi Riau memiliki morfem terikat dan konfiks \{bar-an\}.

\section{SIMPULAN}

Berdasarkan analisis data yang telah dipaparkan dan dijelaskan, penulis dapat menyimpulkan bahwa morfem bahasa Melayu Riau dialek Siak di Desa Rempak Kecamatan Sabak Auh Kabupaten Siak Provinsi Riau memiliki morfem terikat yang mencakup (1) prefiks $\{$ di- $\},\{$ maN- $\},\{$ be- $\},\{$ te- $\},\{$ peN- $\}$, \{pe-\}, \{se-\}, \{per-\}, \{ke-\}, (2) infiks yang terdiri dari $\{-a m-\},\{-a r-\}, \quad\{-a l-\}, \quad(3)$ sufiks terdiri atas $\{-i\},\{-k a n\},\{-a n\}$, (4) konfiks terdiri dari $\{$ ke-an $\},\{$ per-an $\},\{$ be-an $\}$. 
REFERENSI

Alwi, Hasan, dkk. 2003. Tata Bahasa Baku Bahasa Indonesia.Jakarta : Balai Pustaka.

Chaer, Abdul. 2007. Linguistik Umum. Jakarta : PT Rineka Cipta.

Chaer, Abdul. 2008. Morfologi Bahasa Indonesia. Jakarta : PT Rineka Cipta.

Chaer, Abdul. 2009. Fonologi Bahasa Indonesia. Jakarta : PT Rineka Cipta.

Charlina dan Sinaga Mangatur. 2006. Morfologi. Pekanbaru : Cendikia Insani

Depertemen Pendidikan Nasional.2008.Kamus Besar Bahasa Indonesia.Jakarta : PT Gramedia Pustaka Utama.

Faizah, Hasnah. 2009. Mata Kuliah Dasar Umum Bahasa Indonesia. Pekanbaru: Cendikia Insani

Hamidy, U.U. 2011.Jagad Melayu dalam Lintasan Budaya di Riau.Pekanbaru : Bilik Kreatif Press.

Heru Tafiyanto. 2015. Analisis Morfofonemik Pada Cerita Bersambung Pak Guru Dalam Majalah Djaka Lodang Tahun $2012 \quad$ Karya Suhindriyo.Jurnal. Yogyakarta: Universitas Gajah Madah

Mahsun. 2005. Metode penelitian Bahasa. Jakarta : PT Raja Grafindo Persada

Moleong, J.lexy. 2014. Metodologi Penelitian Kualitatif Edisi Revisi. Bandung : PT REMAJA ROSDAKARYA.

Mulyono, Iyo. 2013. Ilmu Bahasa Indonesia Morfologi teori dan Sejumput Problematik terapannya. Bandung : CV YRAMA WIDYA.

Muslich, Masnur. 2010. Tata Bentuk bahasa Indonesia Kajian Ke arah Tata bahasa Deskriptif. Jakarta Timur : PT Bumi Aksara.

Parera.J.D. 2007.Morfologi. Jakarta PT. Gramedia.

Pateda, Mansoer. 1994. Linguistik (Sebuah Pengantar)Bandung : Angkasa

Putrayasa, Ida Bagus. 2010. Kajian Morfologi (bentuk Derivasional dan
Infleksional). Bandung : PT Refika Aditama.

Wulandari, Putri.2012.Afiksasi Dalam Bahasa Jawa dan Bahasa Sunda Dalam Bahasa Indonesia.Jurnal. Medan: UNIMED.

Ramlan, M. 1997. Morfologi Suatu Tinjauan Deskriptif. Yogyakarta : CV Karyono

Sugiyono. 2012. Metode Penelitian Kuantitatif Kualitatif dan $R \& D$. Bandung : Alfabeta

Sujarweni, V.Wiratna. 2014. Metodologi Penelitian Lengkap, Praktis, dan Mudah Dipahami. Yogyakarta : PT. PUSTAKA BARU

Wiyanto, Asul. 2012. Kitab Bahasa Indonesia Untuk SD, SMP, SMA, MAHASISWA, UMUM. Yogyakarta: Percetakan Galang Press.https://www.scrbd.com/mobil e/doc/20709-jamika-mi-Unikomac-id-Data-jurnal-Siak-volume-01jurnal-wartika-pdf). 